\title{
Cholelithiasis in a neonate with Downs syndrome: a case report
}

\author{
Kamalammal $\mathbf{R}^{1}$, Sowmya $\mathbf{S}^{2}$ \\ ${ }^{1}$ Dr. Rugmini Kamalammal, Associate Professor in Pediatrics, Adichunchunagiri Institute of Medical Sciences, Mandya, \\ Karnataka, ${ }^{2}$ Dr Sowmya S, Postgraduate in Pediatrics. Adichunchunagiri institute of Medical Sciences, Mandya, \\ Karnataka. India
}

Address for correspondence: Dr. Rugmini Kamalammal, Email: rugminirao@yahoo.com

\begin{abstract}
Choleithiasis is very rare in neonates. Children with Downs syndrome are at an increased risk of developing lithiasis.There are very few reports of cholelithiasis in infants with Down's syndrome but none in neonates. Here we report a case of Down's syndrome presenting with cholelithiasis in the neonatal period. We highlight the fact that these children should be monitored for cholethithiasis.
\end{abstract}

Keywords: Down's syndrome, Cholelithiasis, Neonate

\section{Introduction}

Down syndrome is the most common chromosomal disorder with an incidence of 1 in 733 live births [1]

The incidence of gallstones in Down syndrome is $6.9 \%$ and biliary sludge is $2.1 \%$. [2].

The constellation of findings in Down syndrome was found to be due to Trisomy 21 in 1959 by Lejeune and his coworkers [2].

Although the typical phenotype of Trisomy 21 hasn't changed over years there have been some reports of rare associations like biliary sludging, cholelithiasis, Meckels diverticulum etc. with Down syndrome [3-5].

We report a newborn with Trisomy 21 who presented with asymptomatic cholelithiasis .

\section{Case Report}

A female neonate with facial dysmorphism [figure:1] born to a 22 year old mother out of a non consanguinous couple was diagnosed with Trisomy 21 in the first week of life. Anomaly scan done on $5^{\text {th }}$ month did not show any anomalies.

Her birth history, family history were not significant. On examination the baby had loose skin over the nape of neck, simian crease[figure:1], hypotonia which is typical of Down syndrome.

Complete blood count, Thyroid profile, Liver Function Test, Serum Cholesterol were within normal limits, peripheral smear showed normocytic normochromic blood picture.

Chest Xray, Echo cardiogram, the cranial ultrasound did not reveal any abnormalities.

The abdominal USG showed normal liver, normal sized gallbladder with normal wall thickness, multiple stones in the gallbladder with size less than $0.5 \mathrm{~mm}$ each [figure:2].

Elder sibling who is 2 years was normal proper counselling regarding prenatal genetic diagnosis was given. 


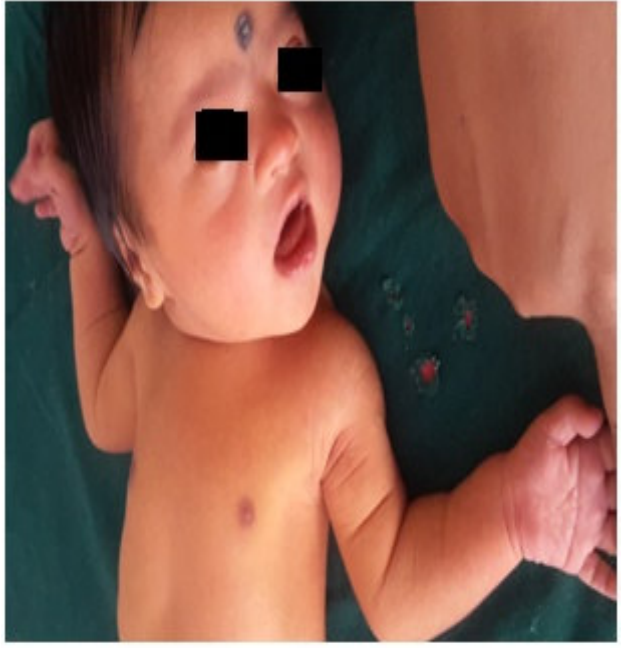

Fig: 1 Baby showing facial dysmorphism, simian crease.

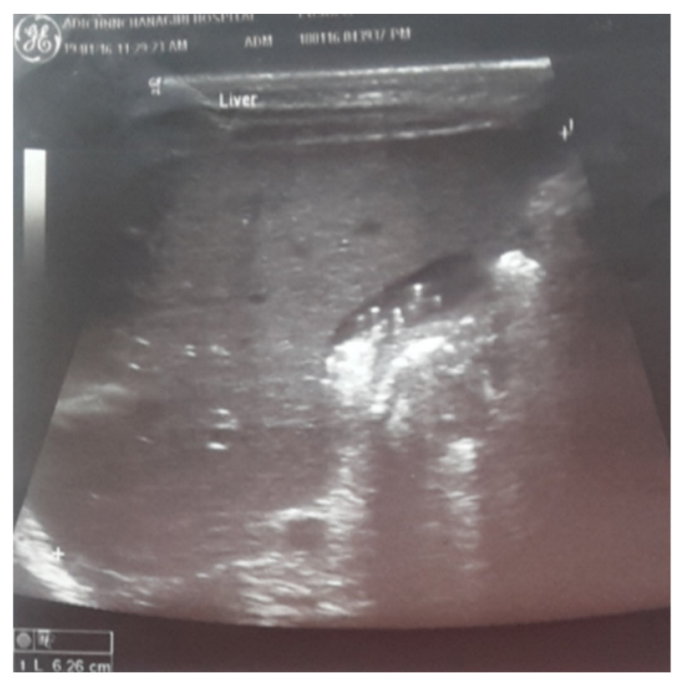

Fig: 2 microlithiasis in gallbladder.

\section{Discussion}

Several conditions are considered to be risk factors for biliary lithiasis among neonates, infants and children: hemolytic disease, cystic fibrosis, ileal resection, hypercholesterolemia, congenital hepatobiliary anomalies, congenital heart disease, prematurity, phototherapy, sepsis, parenteral nutrition, diuretics and antibiotics, particularly ceftriaxone.[3,6-8].

Most Downs syndrome infants with biliary abnormalities will be idiopathic and asymptomatic and has spontaneous resolution .

The pathological mechanism for higher prevalence of gall bladder microlithiasis in DS patients than in the general pediatric population remains unknown, but it could be related to hypercholesterolemia during intrauterine life. [9].

Ultrasound is the investigation of choice for detecting gallbladder abnormalities it has good sensitivity and specificity.[10]

Clinical follow-up and serial ultrasound examinations will demonstrate that most infant remained without symptoms or had spontaneous resolution of the biliary abnormalities in 6 months.[8,11,12].

\section{Reference}

1. Kliegman, stanton, Geme St, Schor. Nelson Textbook of Pediatrics. $20^{\text {th }}$ Edition;81:611.
Patients with biliary lithiasis that did not spontaneously resolve over the next six months received indication for surgical treatment, even if they did not present any symptoms[13] this was reviewed and Only symptomatic children with abdominal pain, vomiting and or cholecystitis symptoms were indicated for surgical procedures [14].

\section{Conclusion}

In most Downs syndrome cases, biliary lithiasis and biliary sludge were non-symptomatic. It could be concluded that gallstones and biliary sludge in Downs syndrome patients mostly had favorable evolution and a good prognosis, with spontaneous resolution and nonsymptomatic presentation in most patients. These patients need to be followed up with serial abdominal ultrasound examinations, and surgical treatment should only be indicated in symptomatic cases or in the presence of cholecystitis. Further studies are needed, in order to investigate the physiopathological mechanisms and high prevalence of these biliary abnormalities in these patients.

Funding: No Funding

Conflict of Interest: The authors declare no conflict of Interes

2. Boëchat MC, Silva KS, Llerena JC Jr, Boëchat PR. Cholelithiasis and Biliary sludge in Downs's syndrome patients. Sao Paulo Med J.2007; 125(6): 329-32. 
3. Chen $\mathrm{MH}$, Chen SJ. Cholelithiasis in Down syndrome. Acta Paediatr.2004;45(5): 269-71.

4. Aynaci FM, Erduran E, Mocan H, Okten A,Sarpkaya AO. Cholelithiasis in Infants with Down syndrome: report of two cases. Ann GastroenterolHepatol.1988;24(1):21-22.

5. Zarnitsky C, Lhuintre JP, Joly JP, Hillemand B.Association of Hirschsprung disease, Meckel's diverticulum and gallbladder calculi in a young Down's syndrome patient. Annales degastroentérologie et d'hépatologie.1988;24(1): 21-22.

6. Mohammad-Reza,Alireza Norouzi.Cholelithiasis in Childhood: A Cohort Study in North of Iran. Iran J Pediatr. 2013 Oct; 23(5): 588-592.

7. Bor O, Dinleyici EC, Kebapci M, Aydogdu SD. Ceftriaxone associatedbiliary sludge and pseudocholelithiasis during childhood. Pediatr Int.2004Jun;46(3):322-4.

8. Rescorla FJ. Cholelithiasis, cholecystitis, and common bile ductstones. Curr Opin Pediatr.1997Jun;9(3):276-82.
9. Bocconi L, Nava S, Fogliani R, Nicolini U. Trisomy 21 is associated with Hypercholesterolemia during Intrauterine life. AmJ Obstet Gynecol. 1997;176(3):540-3.Surg.1992;27(10):1305-7.

10. Yang HL, Li ZZ, Sun YG. Reliability of Ultrasonography in diagnosis of Biliary lithiasis. Chin Med J

(Engl).1990Aug;103(8):638-41.

11. Kumar R, Nguyen K, Shun A. Gallstones and common Bileduct calculi in Infancy and Childhood. Aust N Z J Surg. 2000;70(3):188-91.

12. St-Vil D, Yazbeck S, Luks FI, Hancock BJ, Filiatrault D, Youssef S. Cholelithiasis in Newborns and Infants. J Pediatr.1992Oct;27(10):1305-7

13. Bailey PV, Connors RH, Tracy TF Jr, Sotelo-Avila C, Lewis JE,Weber TR. Changing spectrum of Cholelithiasis and Cholecystitis in Infants and Children. Am J Surg.1989;158(6):585-8.

14. Wesdorp I, Bosman D, de Graaff A, Aronson D, van der BlijF, Taminiau J. Clinical presentations and predisposing factors of cholelithiasis and sludge in children. J Pediatr Gastroenterol Nutr. 2000;31(4):41117.

\section{How to cite this article?}

Kamalammal R, Sowmya S, Cholelithiasis in a neonate with Downs syndrome: a case report. Pediatr rev. Int J Pediatr Re 2016;3(3):196-198.doi:10.17511/ijpr.2016.i03.10. 